\title{
ARTIGOS
}

\section{ATIVIDADE MOLUSCICIDA E CERCARICIDA DE DIFERENTES ESPECCIES DE EUCALYPTUS}

\author{
Nelymar Martineli Mendes, Neusa Araújo, Cecilia Pereira de \\ Souza, José Pedro Pereira e Naftale Katz
}

\begin{abstract}
Os hidrolatos e óleos essenciais de diferentes espécies de Eucalyptus foram testados sobre caramujos adultos e desovas de Biomphalaria glabrata e cercárias de Schistosoma mansoni. Esses produtos foram obtidos por arraste de vapor. Dos 21 hidrolatos ensaiados, oito foram ativos sobre caramujos, nove demonstraram ação sobre desovas e três apresentaram atividade sobre cercárias a partir da diluição de 1:4 (V/V). Dos óleos estudados, 11 tiveram atividade para planorbideos e desovas nas concentrações de $20 \mathrm{ppm}(\mathrm{p} / \mathrm{V})$. O hidrolato do Eucalyptus deanei foi ativo sobre caramujos, desovas e cercárias a partir da diluição de $1: 4$, e o óleo na concentração de 20 ppm.
\end{abstract}

Palavras-chaves: Moluscicida. Cercaricida. Eucalyptus.

Uma medida auxiliar no controle da esquistossomose, doença que ocupa um lugar de destaque entre as endemias brasileiras, é o emprego de moluscicida, visando diminuir o número de moluscos. $\mathrm{Na}$ tentativa de obtenção de moluscicidas naturais, para substituir os sintéticos que são importados e de alto custo, vários pesquisadores vêm estudando a atividade de plantas no Brasil 1234 .

No presente trabalho, são relatados os ensaios em laboratório com hidrolatos, óleos essenciais e extratos aquosos liofilizados de diferentes espécies de Eucalyptus sobre caramujos e desovas de Biomphalaria glabrata e cercárias de Schistosoma mansoni.

\section{MATERIAL E MÉTODOS}

As espécies de Eucalyptus estudadas foram: $E$. botryoides Smith, E. camaldulensis Dehn, $E$. citriodora $\mathrm{Hk}, E$. cloeziana $\mathrm{F}$. Mueller, $E$. deanei Maiden, $E$. dunnii Maiden, E. exserta F. Mueller, E. grandis Hill ex Maiden, E. maculata $\mathrm{Hk}, E$. microcorys F. Mueller, E. nesophyla Blakely, E. paniculata Smith, $E$. phacotricha Blabely Mckie, $E$. pilularis DC, $E$. punctata DC, $E$. resinifera Smith, $E$. robusta Smith, E. rudis Endl, E. saligna Smith, E. tereticornis Smith e E. urophyla S. T. Blake.

As folhas dos Eucalyptus (Myrtaceae), coletadas em maio de 1986, no municipio de Bom Despacho,

Centro de Pesquisas "René Rachou"/Fundação Oswaldo Cruz, Belo Horizonte, MG, Brasil.

Suporte financeiro da Financiadora de Estudos e Projetos (FINEP), convênio n. 42890023.00.

Endereço para correspondência: Dr. Nelymar Martineli Mendes, Av. Augusto de Lima 1715, Barro Preto, 30190 Belo Horizonte, MG, Brasil.

Recebido para publicação em 15/05/90.
MG (Companhia Agricola e Florestal Santa Bárbara) foram expostas ao ar livre para secagem. Os hidrolatos e os óleos essenciais foram obtidos por arraste de vapor. $O$ hidrolato é o codestilado separado do óleo essencial do vegetal ${ }^{3}$. As extrações foram feitas usando-se $50 \mathrm{~g}$ de folhas até a obtenção de um litro de hidrolato. Durante o processo de arraste de vapor a água condensada no balão que continha as folhas formou um extrato aquoso que foi coletado, filtrado em papel de filtro e liofilizado.

Dos 21 Eucalyptus estudados, foram obtidos os óleos essenciais somente das espécies $E$. camaldulensis, $E$. citriodora, $E$. cloeziana, $E$. deanei, $E$. dunnii, E. exserta, E. maculata, $E$. nesophyla, $E$. phacotricha, E. pilularis, E. punctata, E. resinifera, $E$. rudis e $E$. saligna; os demais Eucalyptus não forneceram quantidades suficientes de óleos para os testes biológicos.

Teste como moluscicida - Em cada ensaio, foram usados dez caramujos adultos de $\boldsymbol{B}$. glabrata originários de Justinópolis (MG) e criados em laboratório, e grupos de duas a quatro desovas (52-141 ovos) recolhidos de folhas de polietileno incolores, transparentes, previamente colocados nos aquários para servirem de suporte para a oviposição dos planorbídeos. As conchas dos moluscos mediram de 10-13 mm de diâmetro $\mathrm{e}$ as desovas eram de 0-1 dia de idade.

Os caramujos foram colocados em recipientes com $250 \mathrm{ml}$ da mistura ensaiada, com tampa de malha de náilon, e as desovas em frascos com $10 \mathrm{ml} \mathrm{da}$ mistura.

O tempo de exposição dos moluscos e desovas de $B$. glabrata foi de 24 horas. Em seguida, foram lavados e colocados em água desclorada com tiossulfato de sódio a $2 \%$, permanecendo em observaçāo por mais três dias. Neste periodo, procedeu-se diariamente à troca de água dos recipientes contendo os planorbídeos e as desovas, retirando-se e anotando-se o número de caramujos e embriões mortos. Para os 
Mendes NM, Araújo N, Souza CP, Pereira JP, Katz N. Atividade moluscicida e cercaricida de diferentes espécies de Eucalyptus. Revista da Sociedade Brasileira de Medicina Tropical 23: 197-199, out-dez, 1990.

moluscos sobreviventes foi colocada alface fresca. Considerou-se a mortalidade acumulada durante os quatro dias 2 .

Os óleos essenciais e os extratos aquosos liofilizados foram ensaiados nas concentrações de 1 , 20 e $100 \mathrm{ppm}(\mathrm{p} / \mathrm{V})$ e os hidrolatos não diluidos e nas diluições de $1: 1,1: 4,1: 6,1: 8$ e $1: 10(\mathrm{~V} / \mathrm{V})$.

Teste como cercaricida - Grupos de aproximadamente 500 cercárias de $S$. mansoni foram colocados em $10 \mathrm{ml}$ de misturas de hidrolatos não diluidoe nas diluições de 1:1 e 1:4 e das misturas de óleos nas concentrações de 1,20 e 100 ppm. A observação de cercárias foi feita em microscópio estereoscópio após 5,15 e 30 minutos de contato.

Teste como piscicida - Dez exemplares de Lebistes reticulatus (piaba) foram colocados em frascos com $150 \mathrm{ml}$ de hidrolatos não diluido e nas diluições de 1:1 e 1:4. Decorridas 24 horas de exposição, os peixes foram lavados e deixados em observação em água desclorada, durante três dias. Diariamente, procedia-se à troca da água dos frascos, leitura da mortalidade e retirada dos peixes mortos.

A temperatura e o $\mathrm{pH}$ das misturas testadas sobre caramujos adultos, desovas, cercárias e peixes foram medidos no inicio e no final de cada ensaio. A temperatura variou de 26 a $28^{\circ} \mathrm{C}$ e o pH de 6 a 7 .

Para os grupos controles respectivos, foi usada somente água desclorada.

Foram considerados ativos para caramujos, desovas e cercárias os hidrolatos, os óleos essenciais e os extratos aquosos que apresentaram mortalidade a partir de $90 \%$ ao final do periodo de observação.

\section{RESULTADOS}

$\mathrm{Na}$ Tabela 1 estão representadas as diluições minimas ativas dos hidrolatos sobre caramujos adultos e desovas de $B$. glabrata, cercárias de $S$. mansoni e grupos $L$. reticulatus, e na Tabela 2 as concentrações minimas dos óleos essenciais como moluscicida e cercaricida.

Os extratos aquosos liofilizados das folhas do $E$. nesophyla e $E$. phacotricha apresentaram $100 \%$ de mortalidade para caramujos na concentração de 100 $\mathrm{ppm}$. Os outros extratos não foram ativos para caramujos e desovas.

Nos grupos controles não houve mortalidade.

\section{DISCUSSÃO}

Rouquayrol e cols ${ }^{3}$ estudaram a ação moluscicida de hidrolatos de 82 espécies de vegetais do Nordeste brasileiro, sobre caramujos adultos de $B$. glabrata.

No presente trabalho, foram testados hidrolatos, óleos essenciais e extratos aquosos liofilizados de folhas de várias espécies de Eucalyptus. Os resultados dos ensaios preliminares como moluscicida e cercaricida foram promissores, uma vez que os hidrolatos de oito espécies do gênero Eucalyptus apresentaram atividade sobre caramujos de $B$. glabrata, nove espécies agiram sobre desovas e três demonstraram atividade sobre cercárias de $S$. mansoni $i$ partir da diluição de 1:4 e, os óleos de onze espécies foram ativos sobre caramujos e desovas a partir da concentração de 20 ppm.

Tabela 1 - Atividade de hidrolatos de Eucalyptus sobre caramujos adultos, desovas de Biomphalaria glabrata, cerçárias de Schistosoma mansoni $e$ Lebistes reticulatus (piabas).

\begin{tabular}{|c|c|c|c|c|c|}
\hline \multirow{2}{*}{ Espécie } & \multicolumn{4}{|c|}{ Diluição V/V* (Porcentagem de mortalidade) } & . \\
\hline & Caramujos & Desovas & Cercárias & Peixes & \\
\hline E. botryoides & $1: 4(100)$ & $1: 1(100)$ & $\mathrm{n} / \mathrm{d}(100)$ & 1:1 (100) & \\
\hline E. camaldulensis & $1: 4(90)$ & $\mathrm{n} / \mathrm{d}(100)$ & In $(0)$ & $1: 1(100)$ & \\
\hline E. citriodora & $1: 4(90)$ & $1: 4(100)$ & $\mathrm{n} / \mathrm{d}(100)$ & $1: 4(100)$ & \\
\hline E. cloeziana & $1: 1(90)$ & $1: 4(90)$ & $\mathrm{n} / \mathrm{d}(100)$ & $1: 4(100)$ & \\
\hline E. deanei & $1: 4(100)$ & $1: 8(100)$ & $1: 4(100)$ & $1: 4(100)$ & \\
\hline E. dunnii & $1: 1(100)$ & $1: 1(100)$ & $1: 1(100)$ & $1: 4(100)$ & \\
\hline E. exserta & $1: 1(100)$ & $1: 4(100)$ & $1: 4(100)$ & $1: 4(100)$ & \\
\hline E. grandis & $1: 1(100)$ & $1: 4(100)$ & $1: 1(100)$ & $1: 4(100)$ & $\cdots$ \\
\hline E. maculata & $1: 4(100)$ & $1: 1(100)$ & $1: 1(100)$ & $1: 4(100)$ & \\
\hline E. microcorys & $1: 1 \quad(100)$ & $1: 4(100)$ & $1: 1(100)$ & $1: 4(100)$ & \\
\hline E. nesophyla & $1: 1(100)$ & $1: 1(100)$ & $\mathrm{n} / \mathrm{d}(100)$ & $1: 4(100)$ & \\
\hline E. paniculata & $1: 1(90)$ & $\mathrm{n} / \mathrm{d}(100)$ & In $(0)$ & $1: 1(100)$ & \\
\hline E. phacotricha & $1: 1 \quad(100)$ & $1: 1(100)$ & 1:4 (100) & $1: 1(100)$ & \\
\hline E. pilularis & $1: 4(100)$ & $1: 1(100)$ & $\mathrm{n} / \mathrm{d}(100)$ & $1: 1(100)$ & \\
\hline E. punctata & $1: 1 \quad(100)$ & $1: 4(100)$ & $\mathrm{n} / \mathrm{d}(100)$ & $1: 4(100)$ & \\
\hline E. resinifera & $1: 4(100)$ & $1: 4(90)$ & $\mathrm{n} / \mathrm{d}(100)$ & $\mathrm{n} / \mathrm{d}(100)$ & \\
\hline E. robusta & $1: 4(90)$ & 1:1 (100) & $\mathrm{n} / \mathrm{d}(100)$ & $1: 4(100)$ & \\
\hline E. rudis & $\mathrm{n} / \mathrm{d}(100)$ & $\mathrm{n} / \mathrm{d}(100)$ & $\mathrm{n} / \mathrm{d}(100)$ & $\mathrm{n} / \mathrm{d}(100)$ & \\
\hline E. saligna & $1: 1(100)$ & $1: 1 \quad(100)$ & $\mathrm{n} / \mathrm{d}(100)$ & $\mathrm{n} / \mathrm{d}(100)$ & \\
\hline E. tereticornis & $1: 1(100)$ & $1: 4(100)$ & $1: 1(100)$ & $1: 4(100)$ & \\
\hline E. urophylla & $1: 1(90)$ & $1: 4(100)$ & $1: 1 \quad(100)$ & $1: 4(100)$ & \\
\hline Controle & $(0)$ & $(0)$ & $(0)$ & $(0)$ & \\
\hline
\end{tabular}

* menor diluiçào em que a mistura de hidrolato apresentou mortalidade a partir de $90 \%$. In = inativo: $\mathrm{n} / \mathrm{d}=$ nâo diluida. 
Mendes NM, Araújo N, Souza CP, Pereira JP, Katz N. Atividade moluscicida e cercaricida de diferentes espécies de Eucalyptus. Revista da Sociedade Brasileira de Medicina Tropical 23: 197-199, out-dez, 1990.

Tabela 2 - Atividade de óleos essenciais de Eucalyptus sobre caramujos adultos, desovas de Biomphalaria glabrata e cercárias de Schistosoma mansoni.

\begin{tabular}{|c|c|c|c|}
\hline \multirow{2}{*}{ Espécie } & \multicolumn{3}{|c|}{$\begin{array}{l}\text { Concentração em ppm p/V* } \\
\text { (porcentagem de mortalidade) }\end{array}$} \\
\hline & Caramujos & Desovas & Cercárias \\
\hline E. camaldulensis & $20(100)$ & $20(100)$ & $100(100)$ \\
\hline E. citriodora & In $(0$ & $100(90)$ & $100(100)$ \\
\hline E. cloeziana & $20(100)$ & $20(100)$ & $100(100)$ \\
\hline$E$. deanei & $20(100)$ & $20(100)$ & $20(100)$ \\
\hline E. dunnii & $20(100)$ & $20(100)$ & In $(0)$ \\
\hline$E$. exserta & $20(100)$ & $20(100)$ & In $(0)$ \\
\hline E. maculata & $20(100)$ & $20(100)$ & $100(100)$ \\
\hline E. nesophyla & $20(100)$ & $100(100)$ & - \\
\hline E. phacotricha & $20(100)$ & $20(100)$ & $\ln (0)$ \\
\hline E. pilularis & $100(100)$ & $20(100)$ & \\
\hline E. punctata & $20(100)$ & $20(100)$ & - \\
\hline E. resinifera & $20(100)$ & $20(100)$ & $\overline{-}$ \\
\hline E. rudis & $20(90)$ & $20(100)$ & - \\
\hline E. saligna & $20(100)$ & $20(100)$ & - \\
\hline Controle & $(0)$ & $(0)$ & $(0)$ \\
\hline
\end{tabular}

* menor concentração em que a mistura de óleo apresentou mortalidade a partir de $90 \%$.

In = inativo; $-=$ não foi realizado o teste.

O hidrolato e o óleo do $E$. deanei foram ativos para caramujos, desovas e cercárias. $O$ hidrolato apresentou $100 \%$ de mortalidade para caramujos e cercárias a partir da diluição de 1:4 e para desovas a partir da diluição de 1:8. O óleo mostrou $100 \%$ de mortalidade para caramujos, desovas e cercárias a partir da concentraçāo de 20 ppm e $80 \%$ de mortalidade para caramujos a partir da concentração de 1 ppm.

Somente os extratos aquosos de E. nesophyla e $E$. phacotricha demonstraram atividade sobre caramujos na concentração de $100 \mathrm{ppm}$.

Rouquayrol e cols ${ }^{3}$ observaram a ação sobre caramujos adultos de B. glabrata das folhas do hidrolato da $E$. citriodora a partir da diluição de $1: 20$ e no presente trabalho o hidrolato da mesma espécie apresentou atividade sobre caramujos adultos e desovas de B. glabrata a partir da diluição de 1:4.

Os extratos das espécies de Eucalyptus cujos hidrolatos e óleos essenciais demonstraram atividade para caramujos adultos e desovas (E. cloeziana, $E$. deanei, E. exserta, E. maculata, E. punctata e $E$. resinifera) serão fracionados, identificados os seus componentes quimicos e testados como moluscicida e/ou cercaricida.

\section{$S U M M A R Y$}

Hydrolates and essential oils of several Eucalyptus species were tested on adult snails and egg masses of Biomphalaria glabrata, and cercaria of Shistosoma mansoni. These products were obtained by vapor dragging. Eight out of 21 hydrolates presented activity on snails, nine on egg masses and three on cercaria at 1:4 dilutions. Eleven oils were active on both snails and egg masses at $20 \mathrm{ppm}$ concentrations. The hydrolate of $\mathrm{E}$. deanei was active both on snails, egg masses and cercaria at 1:4 dilution and its essential oil at $20 \mathrm{ppm}$.

Key-words: Molluscicides. Cercaricides. Eucalyptus.

\section{AGRADECIMENTOS}

Ao Dr. Elisier Lima Gonçalves, gerente do projeto CAFLORA da Companhia Agricola e Florestal, pelo fornecimento das 21 espécies de Eucalyptus e a Profa Telma Sueli Mesquita Grandi do Departamento de Botânica da Universidade Federal de Minas Gerais, por catalogar algumas espécies de Eucalyptus no herbário da UFMG.

\section{REFERÊNCIAS BIBLIOGRÁFICAS}

1. Mendes, NM, Pereira JP, Souza CP, Azevedo MLL. Ensaios preliminares em laboratório para verificar a ação moluscicida de algumas espécies da flora brasileira. Revista de Saúde Pública 18: 348-354, 1984.

2. Mendes NM, Souza CP, Araújo N, Pereira JP, Katz N. Atividade moluscicida de alguns produtos naturais sobre Biomphalaria glabrata. Memórias do Instituto Oswaldo Cruz 81: 87-91, 1986.

3. Rouquayrol MZ, Fonteles MC, Alencar JE, Matos FJA, Craveiro AA. Atividade moluscicida de óleos essenciais de plantas do Nordeste Brasileiro. Revista Brasileira de Pesquisas Médicas e Biológicas 13: 135 143, 1980.

4. Souza CP, Azevedo MLL, Lopes JLC, Sarti Sarti SJ, Santos Filho D, Lopes JNC, Vichnewski W, Nasi AMTT, Leitão Filho HF. Quimioprofilaxia da esquistossomose: Atividade moluscicida de produtos naturais - Ensaios com caramujos adultos e desovas. Anais da Academia Brasileira de Ciências 56: 333-338, 1984. 